\title{
A study of BIPV net-zero energy building
}

\author{
Szu-Chi Kuan", Chi-Chang Chan, Chun-Ming Shu
}

Green Energy \& Environment Research Laboratories, Industrial Technology Research Institute, Hsinchu, Taiwan

\begin{abstract}
The purpose of this paper is to analyze the power performance and power generation of a BIPV system built in HsinChu, Taiwan, during 2011-2012. The total PV energy generation is 5,960 kWh and the energy consumption is 7,257 $\mathrm{kWh}$ in 2011. After insulation works and setting the standards of electrical equipment operating time, the BIPV building achieves net zero energy goal in 2012. The total PV energy generation is 5,329 $\mathrm{kWh}$ and the energy consumption is $4,202 \mathrm{kWh}$. The self-powered ratio of renewable energy was $126.8 \%$ in the whole BIPV house. In this research, we investigated on the four different types of PV module for the net zero energy research project. The total system capacity is $8.04 \mathrm{kWp}$, and the system was installed at sloping roof, wall, window and shading. The BIPV Experiment-Demo House is a good example of using renewable energy and some energy saving measures to achieve net zero energy building.
\end{abstract}

Keywords: Net zero energy, building integrated photovoltaics (BIPV), photovoltaics system

\section{Introduction}

In recent years, the European Union, the United States and other advanced countries have issued the design or construction case of zero-energy building (or nearly zero energy building). In addition, Goals for the implementation of zero energy buildings are discussed and proposed at the international level. For example, the European Union has set ambitious targets to ensure that from 2020 all new buildings consume very little energy and it has created the term "nearly zero-energy building" or nZEB. And the United States Department of Energy has launched its net zero energy commercial buildings initiative (CBI) to support the goal of net zero energy for all new commercial buildings by $2030,50 \%$ of all commercial building stock by 2040, and all commercial buildings by 2050 [1].

The net zero energy is the main target of the BIPV house in Taiwan, which was built by using four different types of PV module. Building integrated photovoltaics (BIPV) refers to the integration of photovoltaic $(\mathrm{PV})$ devices into the building envelope, replacing traditional materials with those that serve as building skin and solar power generator [2]. The BIPV is not only one of the solutions to save the energy from building but also can produce the energy for people using.

This research aims on the energy balance of energy generation and energy consumption in BIPV system. The BIPV system is located at the Industrial Technology Research Institute (ITRI), Hsinchu, Taiwan, and the front of the building face to the east-south site. In this paper, we mainly focus on the electrical output and power consumption data from 2011 to 2012. According to the first-year experience data (2011), we find the PV power generation cannot balance total electrical loads in the BIPV building. The main reason is that the double glass BIPV modules cannot insulate heat and increase air conditioner load. Therefore, we do the research about energy conservation improvement and enhancement of PV power generation in the building. Based on full year of energy performance data in 2012, the building is achieving net zero energy performance!

\footnotetext{
* Manuscript received May 6, 2013; revised July 22, 2013.

Corresponding author. Tel.: +886-937538651; E-mail address: SCKuan@itri.org.tw.
} 


\section{Project Discussions}

\subsection{Information of the BIPV building}

The BIPV Net-zero Energy Experiment-Demo House is separated into two parts, showroom and office respectively. In the office, there are four people working inside and setting-up the indoor temperature in $26^{\circ} \mathrm{C}$ with air condition. The total area of each room is $32.5 \mathrm{~m}^{2}$, whose scale is around $5.5 \mathrm{~m} \times 5.9 \mathrm{~m}$ (see Fig. 1).

In this study, four different types of PV modules were used in the BIPV building to investigate the actual power generation characteristics of the system to achieve net-zero energy construction requirements $[3,4]$.
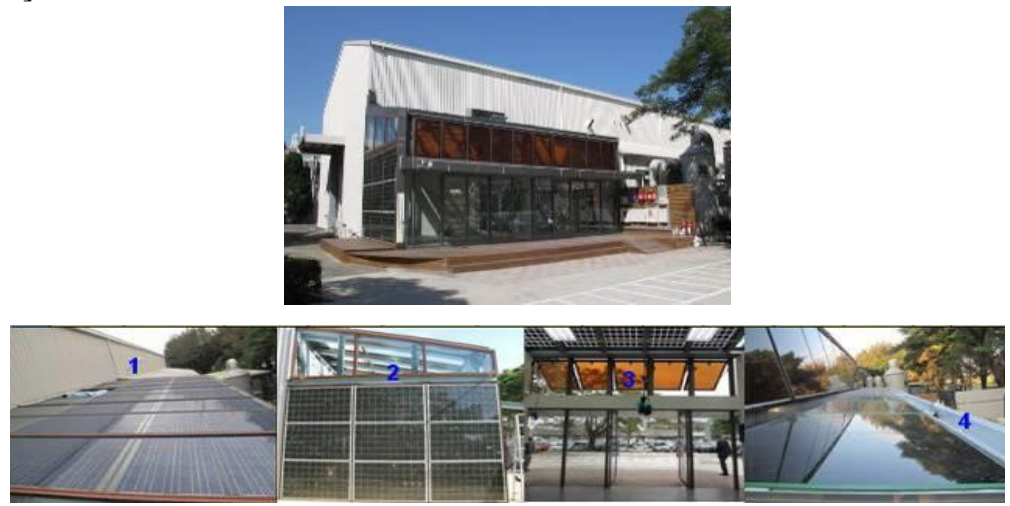

Fig. 1. The four different types of PV module were installed on different building surface.
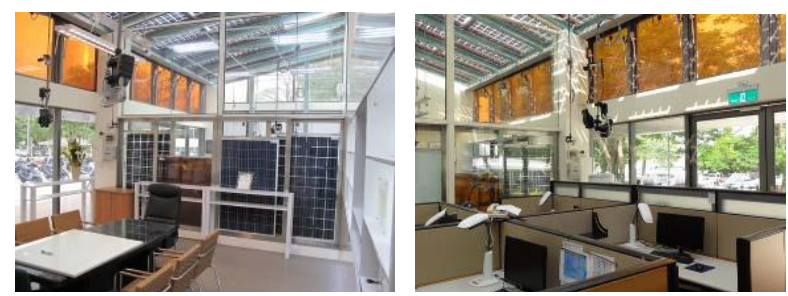

Fig. 2. BIPV exhibition room (left) and the office of the internal appearance of the (right).

Table 1. Four different PV modules on the surface of BIPV building

\begin{tabular}{lllll}
\hline \hline & \multicolumn{3}{c}{ BIPV Research Building } & \\
System setting & $\# 1$ & $\# 2$ & $\# 3$ & $\# 4$ \\
\hline setting & Roof & Wall & Window & shading \\
Cell type & $c-S i$ & $c-S i$ & a-Si (HCRI) & uc-Si(Tandem) \\
Capacity $\left(W_{p}\right)$ & 4,200 & 1,890 & 750 & 1,200 \\
Module scale $(m m)$ & $1760 \times 1066$ & $1657 \times 991$ & $1300 \times 1100$ & $1300 \times 1700$ \\
Modules (pic.) & 20 & 9 & 10 & 10 \\
Module efficiency $\left(\eta_{p v}\right)$ & $11.19 \%$ & $12.79 \%$ & $5.24 \%$ & $8.39 \%$ \\
\hline \hline
\end{tabular}

The total system capacity is $8.04 \mathrm{kWp}$. In this building, the photovoltaic solar cells used in the modules are 1) $4.2 \mathrm{kWp}$ poly-silicon double-sided glass modules (light through modules) installed at sloping roof, 2) $1.89 \mathrm{kWp}$ color poly-silicon single-sided opacity glass modules installed at the right side of the building wall, 3) $0.75 \mathrm{kWp}$ amorphous silicon thin-film modules installed at the facade electric windows site, and 4) $1.2 \mathrm{kWp}$ stack-type membrane modules (Tandem) installed at the façade awning site, as shown in Table 1. Each PV module was connected with appropriate inverter to realize the establishment of indoor energy consumption, including room temperature and humidity control, illumination, outdoor power equipment, sunlight intensity, environmental temperature and humidity, and wind speed monitoring systems to provide long-term testing and empirical research data. 


\subsection{Improvement of energy consumption}

The BIPV net-zero energy experiment-demo house has two rooms, one is a showroom and the other is a four person office. Based on the space planning, we furnished rooms with necessary equipment. Office electrical loads include air conditioner, lighting lamps, fire equipment, fans, refrigerators, water dispensers, and general office equipment such as computers, monitors, telephones, fax machines, copiers and monitoring equipment, etc. The showroom has air conditioner, lighting equipment, projector equipment, fire equipment, large LCD display, monitoring equipment and other presentation electricity equipment. Because the double glass BIPV modules allow sunlight to penetrate into the house, and hence increase indoor temperatures and air conditioning loads. According to the simulations of building energy consumption and electricity generation in BIPV systems, we find a better solution to improve the energy consumption in the BIPV house, including the natural ventilation design and insulation work in roof, and loading usage scheduling. We set the standards of electrical equipment operating time, as shown in Table 2. On working days from Monday to Friday, 8:00 to 17:00, electric loads operate normally. On the other hand, on Saturday, Sunday and public holidays, the loads should be turn off or operate at a low power state. In this experiment, we follow the rules to use loads and do not control the usage of loads too much as far as possible to not affect power consumption. We hope not only to maintain comfort in the rooms, but also can achieve energy saving and carbon reduction.

Table 2. The standards of electrical equipment operating time

\begin{tabular}{llll}
\hline \hline Equipment & Date & Operation time & Notes \\
\hline Office Air conditioning & Working day & 08:00AM 17:00PM & Temperature $: 27^{\circ} \mathrm{C} \pm 1^{\circ} \mathrm{C}$ \\
Showroom Air conditioning & Working day & Meeting Time & Temperature $: 27^{\circ} \mathrm{C} \pm 1^{\circ} \mathrm{C}$ \\
Computers in office & Working day & 08:00AM 17:00PM & -- \\
Office lighting & Working day & 08:00AM 17:00PM & When illumination $<500$ lux \\
Showroom lighting & Working day & $08: 00 \mathrm{AM} \sim 17: 00 \mathrm{PM}$ & When illumination $<500$ lux \\
Fans & Working day & $08: 00 \mathrm{AM} \sim 17: 00 \mathrm{PM}$ & Not open in winter \\
Qater dispenser & Working day & 07:00AM 18:00PM & Use a low power state at other times \\
Multi-function printer & Open all year & Open all day & When not use, it is in idle status. \\
Refrigerator & Open all year & Open all day & At lower temperatures \\
Monitoring machines & Open all year & Open all day & -- \\
Fire equipment & Open all year & Open all day & -- \\
Office receptacle & Working day & 07:00AM 18:00PM & Turn off at other times \\
Showroom receptacle & Working day & $07: 00 \mathrm{AM} \mathrm{18:00PM}$ & Turn off at other times \\
Electric Window & Working day & Turn off device if not used & \\
Exhibition equipment & Working day & Open during the exhibition period \\
\hline \hline
\end{tabular}

\subsection{Monitoring discussion}

The factors of the wireless monitoring study include irradiation, indoor temperatures, indoor illumination, temperature and wind velocity of the surrounding, the power performance and energy loading. A data acquisition system was installed to determine if the building met its energy design goal of zero energy. In this case, we compare 2012's data with 2011's data. There are two wireless meter to monitor the DC string from PV system and the AC string from the power inverter. The energy loading setting is in the AC site. It also has a meter at the end of the on-grid system to monitor the power. The energy measurements were following the test standard of IEC 61724 [5]. In order to evaluate system performance, the pyranometer was coincided with ISO 9060 Second Class, where the irradiation data was sampled each time pre- ten seconds and recorded each time pre- minute.

\subsection{BIPV system performance}

Two performance indicators are used to assess long-term operational performance [6], which are Daily Mean Yield (DMY), Performance Ratio (PR), as follows. The DMY and PR can be obtained by Eq. (1) and Eq. (2) respectively to analyze the efficiency on the power output of the research PV systems. The study presented a result consistent with monthly irradiation tendency, where the system performance was 
influenced with the inclinations by sun revolution trajectory.

$$
\begin{aligned}
& \mathrm{DMY}=\frac{E_{\text {out }} / \text { day }}{P_{0}} \\
& \mathrm{PR}=\frac{E_{\text {out }} / P_{0}}{H_{I} / G_{0}}
\end{aligned}
$$

where $E_{\text {out }}$ is the system net $\mathrm{AC}$ energy output in $\mathrm{kWh}, P_{0}$ is the system rating power in $\mathrm{kWp}, H_{I}$ is the total in-plane irradiation in $\mathrm{kWh} / \mathrm{m}^{2}$, and $G_{0}$ is the reference irradiance (usually $1 \mathrm{~kW} / \mathrm{m}^{2}$ ).

\section{Results and Discussion}

In this section, we compare the monitoring data of BIPV building's performance in 2011 and 2012. In 2011-the first year research, the BIPV building is not yet a net zero energy building. So we did the research about energy conservation improvement and enhancement of PV power generation in the building. In 2011, the PV power generation of BIPV building is 5,864 kWh. In 2012, the PV power generation is $5,329 \mathrm{kWh}$, approximately $535 \mathrm{kWh}$ less than the last year. Table 3 . shows the values of the Performance Ratio (PR) for the four different types of PV systems on the BIPV study project in 2011. The average of the PR values is $81.69 \%$ for roof top, $66.46 \%$ for the side wall, $72.55 \%$ for the window site and $56.72 \%$ for the shading system. The PR value of shading system is less than $70 \%$ of the average PR value. Because the inclination angle of the shading system was 10 degree only and the system faced to southeastern position, the power performance is inferior to anticipated. Table 4 shows the value of the Daily Mean Yields (DMY) for the four different types of PV system on the BIPV study project in 2011. The average value of the Daily Mean Yields (DMY) is $2.7 \mathrm{kWh} /$ day/kWp for roof top, the 0.9 $\mathrm{kWh} /$ day $/ \mathrm{kWp}$ for the side wall, the $1.3 \mathrm{kWh} /$ day $/ \mathrm{kWp}$ for the window site, and the $1.9 \mathrm{kWh} /$ day $/ \mathrm{kWp}$ for the shading system. The main power generation is from roof system, because it can receive more quantity of solar radiation.

Table 3. The value of the performance ratio for the four different types of PV system on the BIPV study project in 2011 [7]

\begin{tabular}{lllll}
\hline \hline \multirow{2}{*}{ Month } & \multicolumn{4}{c}{ PR (performance ratio) / $\%$ ) } \\
\cline { 2 - 5 } & Roof & Wall & Window & Shading \\
\hline January & $91 \%$ & $62 \%$ & $64 \%$ & $64 \%$ \\
February & $89 \%$ & $61 \%$ & $71 \%$ & $61 \%$ \\
March & $89 \%$ & $68 \%$ & $63 \%$ & $59 \%$ \\
April & $84 \%$ & $77 \%$ & $72 \%$ & $56 \%$ \\
May & $83 \%$ & $72 \%$ & $64 \%$ & $57 \%$ \\
June & $79 \%$ & $71 \%$ & $65 \%$ & $56 \%$ \\
July & $78 \%$ & $69 \%$ & $63 \%$ & $57 \%$ \\
August & $76 \%$ & $70 \%$ & $75 \%$ & $55 \%$ \\
September & $78 \%$ & $66 \%$ & $70 \%$ & $60 \%$ \\
October & $80 \%$ & $56 \%$ & $92 \%$ & $53 \%$ \\
November & $75 \%$ & $59 \%$ & $98 \%$ & $47 \%$ \\
December & $78 \%$ & $58 \%$ & $72 \%$ & $58 \%$ \\
average & $81.69 \%$ & $66.46 \%$ & $72.55 \%$ & $56.72 \%$ \\
\hline \hline
\end{tabular}

Table 4. The value of the daily mean yields for the four different types of PV system on the BIPV study project in 2011 [7]

\begin{tabular}{lllll}
\hline \hline \multirow{2}{*}{ Month } & \multicolumn{4}{l}{ DMY/(kWh/day/kWp) } \\
\cline { 2 - 5 } & Roof & Wall & Window & Shading \\
\hline January & 1.6 & 0.6 & 0.8 & 1.1 \\
February & 2.2 & 0.9 & 1.1 & 1.5 \\
March & 1.8 & 0.6 & 0.6 & 1.1 \\
April & 3.1 & 1.1 & 1.3 & 2.0 \\
May & 2.7 & 0.8 & 0.9 & 1.8 \\
June & 3.7 & 1.0 & 1.2 & 2.6 \\
July & 3.8 & 1.0 & 1.3 & 2.8 \\
August & 3.5 & 1.1 & 1.6 & 2.5 \\
September & 3.5 & 1.2 & 1.6 & 2.7 \\
October & 2.9 & 1.1 & 2.1 & 1.9 \\
November & 1.9 & 0.9 & 1.7 & 1.2 \\
December & 1.6 & 0.7 & 1.1 & 1.2 \\
average & 2.7 & 0.9 & 1.3 & 1.9 \\
\hline \hline
\end{tabular}

Table 5 shows the values of the performance ratio (PR) for the four different types of PV system on the BIPV building in 2012. The average of the PR value is $73 \%$ for roof top, $65 \%$ for the side wall, $81 \%$ for the window site and $51 \%$ for the shading system. Table 6 shows the values of the daily mean Yields (DMY) for the four different types of PV system on the BIPV study project in 2012. The average of the DMY values is $2.4 \mathrm{kWh} / \mathrm{day} / \mathrm{kWp}$ for roof top, $0.9 \mathrm{kWh} / \mathrm{day} / \mathrm{kWp}$ for the side wall, $1.4 \mathrm{kWh} / \mathrm{day} / \mathrm{kWp}$ for 
the window site and $1.7 \mathrm{kWh} / \mathrm{day} / \mathrm{kWp}$ for the shading system. Based on overall analysis of the four different types of PV system on the BIPV house, the power output of each PV system is less 4\% 12\% than last year. The mainly reason is because the life decay of PV modules or the surface of modules is too dirty.

Table 5. The value of the Performance Ratio (PR) for the four different types of PV system on the BIPV study project in 2012

\begin{tabular}{lllll}
\hline \hline \multirow{2}{*}{ Month } & \multicolumn{4}{c}{ PR (performance ratio) / (\%) } \\
\cline { 2 - 5 } & Roof & Wall & Window & Shading \\
\hline January & $76 \%$ & $60 \%$ & $69 \%$ & $56 \%$ \\
February & $80 \%$ & $62 \%$ & $85 \%$ & $56 \%$ \\
March & $74 \%$ & $54 \%$ & $83 \%$ & $51 \%$ \\
April & $72 \%$ & $68 \%$ & $76 \%$ & $53 \%$ \\
May & $69 \%$ & $71 \%$ & $81 \%$ & $48 \%$ \\
June & $69 \%$ & $74 \%$ & $74 \%$ & $51 \%$ \\
July & $67 \%$ & $70 \%$ & $89 \%$ & $46 \%$ \\
August & $71 \%$ & $66 \%$ & $79 \%$ & $50 \%$ \\
September & $72 \%$ & $64 \%$ & $82 \%$ & $50 \%$ \\
October & $73 \%$ & $65 \%$ & $91 \%$ & $48 \%$ \\
November & $74 \%$ & $65 \%$ & $83 \%$ & $50 \%$ \\
December & $74 \%$ & $66 \%$ & $79 \%$ & $52 \%$ \\
average & $73 \%$ & $65 \%$ & $81 \%$ & $51 \%$ \\
\hline \hline
\end{tabular}

Table 6. The value of the Daily Mean Yields (DMY) for the four different types of PV system on the BIPV study project in 2012

\begin{tabular}{lllll}
\hline \hline \multirow{2}{*}{ Month } & \multicolumn{4}{c}{ DMY/(kWh/day/kWp) } \\
\cline { 2 - 5 } & Roof & Wall & Window & Shading \\
\hline January & 1.3 & 0.6 & 0.8 & 1.0 \\
February & 1.4 & 0.6 & 1.0 & 1.0 \\
March & 2.2 & 0.7 & 1.3 & 1.5 \\
April & 2.2 & 0.7 & 1.1 & 1.6 \\
May & 2.9 & 0.9 & 1.4 & 2.0 \\
June & 2.8 & 1.0 & 1.1 & 2.1 \\
July & 3.6 & 1.1 & 1.8 & 2.5 \\
August & 2.8 & 0.9 & 1.5 & 2.0 \\
September & 2.9 & 1.1 & 1.7 & 2.0 \\
October & 2.9 & 1.3 & 2.2 & 1.9 \\
November & 1.8 & 1.0 & 1.4 & 1.2 \\
December & 1.6 & 0.8 & 1.2 & 1.1 \\
average & 2.4 & 0.9 & 1.4 & 1.7 \\
\hline \hline
\end{tabular}

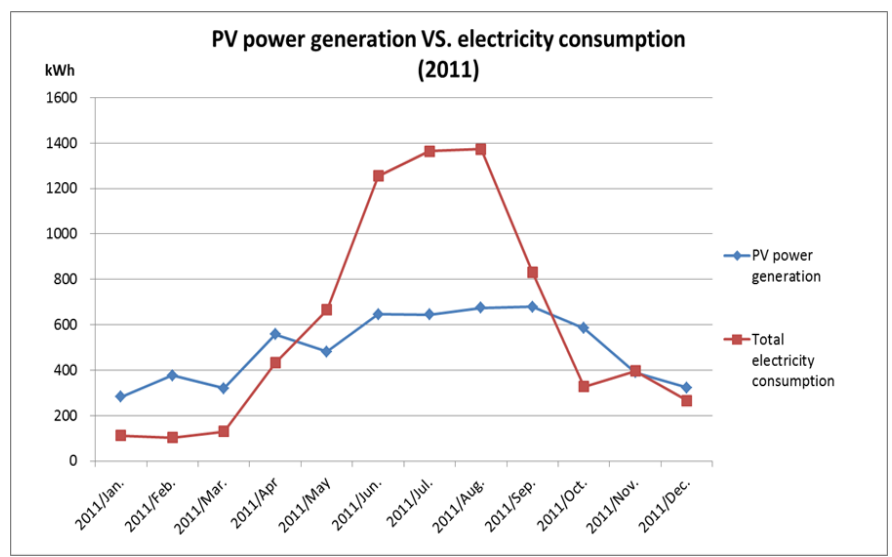

Fig. 3. The PV power generation and electricity consumption in BIPV building, 2011.

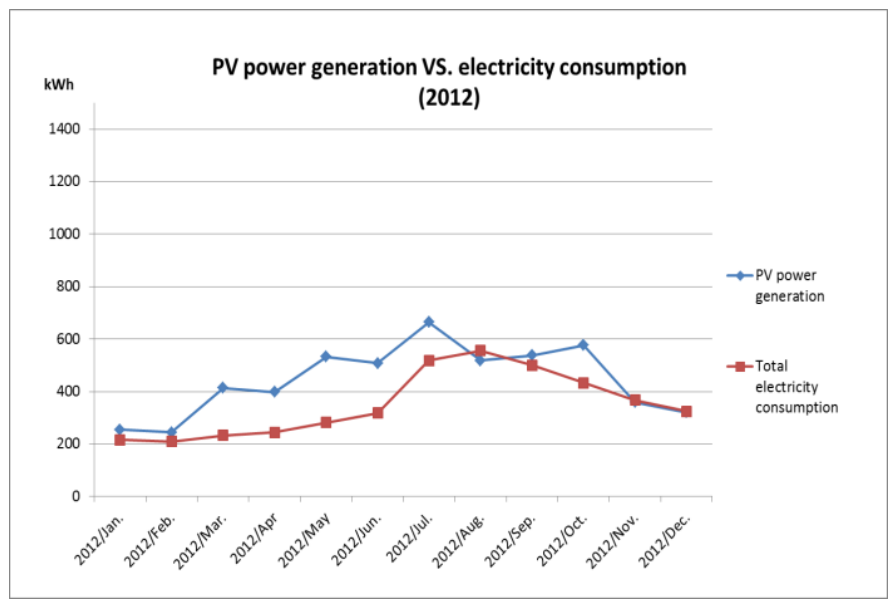

Fig. 4. The PV power generation and electricity consumption in BIPV building, 2012. 
Fig. 3 illustrates the PV power generation and electricity consumption in BIPV building in 2011. From May to September, the total electricity consumption is more than PV power generation. The reason is the double glass BIPV modules allow sunlight to penetrate into the house, and we did not use any insulation material on the roof in 2011. Fig. 4 shows the PV power supply can provide enough electricty to use in the building except in August.

In 2011, the self-powered ratio of renewable energy in BIPV building is $82 \%$. But after improvement of energy consumption, from 2012.01 to 2012.12 , the self-powered ratio of renewable energy was $126.8 \%$ in the whole BIPV house, as shown in Table 7.

Table 7. Self-powered ratio in 2011 and 2012

\begin{tabular}{lll}
\hline \hline Parameter & $2011.01 \sim 2011.12$ & $2012.01 \sim 2012.12$ \\
\hline Electricity Generating Capacity & $5,960 \mathrm{kWh}$ & $5,329 \mathrm{kWh}$ \\
Total Power Consumption & $7,257 \mathrm{kWh}$ & $4,202 \mathrm{kWh}$ \\
Self-powered Ratio & $82 \%$ & $126.8 \%$ \\
\hline \hline
\end{tabular}

\section{Conclusions}

The BIPV case study aims at the energy balance between energy generation and energy consumption. We replaced the outer wall of an old building with four different types of PV modules in this BIPV case study, so the mounting position and direction angle are not suitable for the best energy design in PV setting that mounting position shall face to the south and direction angle is 20 degree in Taiwan. In 2011, the self-powered ratio of renewable energy in BIPV building is only $82 \%$. Even so, after a double wall construction, roof insulation works and cleaning PV panels periodically, the average self-powered ratio in 2012 is $126.8 \%$ from the monitoring of the BIPV system for 2012 whole year in this study, and the BIPV building is truly a net zero energy house in Taiwan. We overcome the poor geographical conditions to achieve an objective of net zero energy building. In the comprehensive research, we analyze all data including irradiation, indoor temperatures, indoor illumination, temperature and wind velocity of the surrounding, the power performance, and energy loading. Although the DMY value and performance ratio for the four different types of PV system on the BIPV building decreased in 2012 compared to that in 2011, the PV system on the building still can produce enough electricity to use. The BIPV ExperimentDemo House is a good example of using renewable energy and some energy saving measures to achieve net zero energy building.

\section{Acknowledgements}

This research was founded by contract 102-D0305 from the Bureau of Energy, Ministry of Economy Affairs.

\section{References}

[1] Torcellini P, Pless S, Lobato C, Hootman T. Main street net-zero energy buildings: The zero energy method in concept and practice. Presented at: 2010 ASME International Conference on Energy Sustainability.

[2] Peng C, Huang Y, Wu Z. Building-integrated photovoltaics (BIPV) in architectural design in China. Energy and Buildings, 2011; 43(12):3592-3598.

[3] Marszal AJ, Heiselberg P, Bourrelle JS, Musall E, Voss K, Sartori I, Napolitano A. Zero energy building - a review of definitions and calculation methodologies. Energy and Buildings, 2011; 43(4):971-979.

[4] Sartori I, Napolitano A, Voss K. Net zero energy buildings: a consistent definition framework. Energy and Buildings, May 2012; 48:220-232.

[5] Performance Monitoring-Guidelines for Measurement, Data Exchange, and Analysis, IEC Standard 61724, Geneva, Switzerland.

[6] Yoon JH, Song J, Lee SJ. Practical application of building integrated photovoltaic (BIPV) system using transparent amorphous silicon thin-film PV module. Solar Energy, 2011; 85(5):723-733.

[7] Chen HJ, Chan CC, Huang CY, Shu CM. A full year BIPV case study on power performance research of four different PV modules. Presented at: 2012, European Photovoltaic Solar Energy Conference. 